OPEN ACCESS

Edited by: Alain Le Moine, Université libre de Bruxelles, Belgium

Reviewed by:

Caroline La, Free University of Brussels, Belgium Swastika Sur, University of California, San Francisco, United States

*Correspondence: Yuji Nozaki yuji0516@med.kindai.ac.jp

Specialty section: This article was submitted to Nephrology, a section of the journa

Frontiers in Medicine

Received: 08 December 2020 Accepted: 08 February 2021 Published: 01 March 2021

Citation: Hirooka Y and Nozaki Y (2021) Interleukin-18 in Inflammatory Kidney

Disease. Front. Med. 8:639103 doi: 10.3389/fmed.2021.639103

\section{Interleukin-18 in Inflammatory Kidney Disease}

\author{
Yasuaki Hirooka ${ }^{1}$ and Yuji Nozaki ${ }^{2 *}$ \\ ${ }^{1}$ Department of Rheumatology, Kindai University Nara Hospital, Nara, Japan, ${ }^{2}$ Department of Hematology and \\ Rheumatology, Kindai University School of Medicine, Osaka, Japan
}

Interleukin (IL)-18, a member of the IL-1 superfamily, is a pro-inflammatory cytokine that is structurally similar to IL-1 $\beta$. IL-18 promotes the production of interferon gamma (IFN- $\gamma$ ) and strongly induces a Th1 response. IL-18 drives the same myeloid differentiation factor 88 (MyD88)/nuclear factor kappa B (NF-kB) signaling pathway as IL-1 $\beta$. In physiological conditions, IL-18 is regulated by the endogenous inhibitor IL-18 binding protein (IL$18 \mathrm{BP})$, and the activity of $\mathrm{IL}-18$ is balanced. It is reported that in several inflammatory diseases, the IL-18 activity is unbalanced, and IL-18 neutralization by $\mathrm{IL}-18 \mathrm{BP}$ is insufficient. IL-18 acts synergistically with IL-12 to induce the production of IFN- $\gamma$ as a Th1 cytokine, and IL-18 acts alone to induce the production of Th2 cytokines such as IL-4 and IL-13. In addition, IL-18 alone enhances natural killer (NK) cell activity and FAS ligand expression. The biological and pathological roles of IL-18 have been studied in many diseases. Here we review the knowledge regarding IL-18 signaling and the role of IL-18 in inflammatory kidney diseases. Findings on renal injury in coronavirus disease 2019 (COVID-19) and its association with IL-18 will also be presented.

Keywords: IL-18, inflammatory kidney disease, inflammation, IL-1, COVID-19

\section{INTRODUCTION}

Inflammation is a defense mechanism that is caused by harmful stimuli and conditions such as infection and tissue injury (1). Innate immunity is the host's first line of defense against pathogens and is activated by pattern recognition receptors (PRRs). PRRs recognize pathogenassociated molecular patterns (PAMPs) and danger-associated molecular patterns (DAMPs) that are common to pathogens. There are several classes of PRRs, including Toll-like receptors (TLRs), C-type lectin receptors, nucleotide-binding oligomerization domain-like receptors (NLRs), retinoic acid-inducible gene-I-like receptors (RLRs), and absent in melanoma 2 (AIM2)-like receptors. The inflammasome, a multiprotein complex formed intracellularly in response to PAMPs and DAMPs, converts procaspase- 1 to active caspase- 1 and induces pro-inflammatory cytokines such as interleukin 1beta (IL-1 $\beta$ ) and IL-18 (2).

The NLR family member leucine rich repeat and pyrin domain containing 3 (NLRP3) forms the NLRP3 inflammasome together with the adapter molecules apoptosis-associated speck-like protein containing a caspase recruitment domain (ASC) and procaspase- 1 and activates caspase- 1 to processes IL-1 $\beta$ and IL-18 to the bioactive mature form $(3,4)$. The NLRP3 inflammasome has been implicated in the pathogenesis of many diseases, including microbial pathogens, inflammatory diseases, cancer, and metabolic and autoimmune disorders $(3,4)$, and it has also been implicated in various kidney diseases (5). A member of the IL-1 superfamily, IL-18 is a pro-inflammatory cytokine that is structurally similar to IL- $1 \beta(6,7)$. IL-18 promotes the production of interferon gamma (IFN- $\gamma$ ) and strongly induces a Th1 response (8). 
In recent years, the biological and pathological roles of IL-18 have been studied in many diseases. Inflammation underlies the pathogenesis of many acute or chronic kidney diseases, and IL-18 plays an important role. This paper focuses on the roles of IL-18 in inflammatory kidney diseases. We review the current knowledge regarding IL-18 signaling, and we outline the existing evidence about the roles of IL-18 in inflammatory kidney diseases. We are in the midst of an epidemic of coronavirus disease 2019 (COVID-19). Findings on renal injury in cases of COVID-19 and its association with IL-18 will also be presented.

\section{THE PRODUCTION AND PROCESSING OF IL-18}

IL-18 was initially identified as IFN- $\gamma$-inducing factor (IGIF) in sera from Propionibacterium acnes-primed and lipopolysaccharide (LPS)-challenged mice (9-11). Although IL18 and IL- $1 \beta$ share only about $17 \%$ sequence homology, they have a common $\beta$-pleated sheet structure $(12,13)$. IL-18 is produced by macrophages, dendritic cells, epithelial cells, keratinocytes, chondrocytes, osteoblasts, synovial fibroblasts, and adrenal cortex cells, and it plays an important role in inflammatory pathology $(7,13,14)$. In the kidney, the predominant source of IL-18 production is tubular epithelial cells (15-17). IL-18 gene expression may be enhanced by stimulation with microbe products such as LPS and by cytokines such as IFN- $\alpha / \beta / \gamma$ and TNF- $\alpha(13,18,19)$. IL-18 is stored intracellularly as a biologically inactive $24-\mathrm{kDa}$ precursor (pro-IL-18), similar to IL- $1 \beta$, and is secreted extracellularly as the $18-\mathrm{kDa}$ bioactive mature molecule after being cleaved by caspase-1. Nitric oxide suppresses the secretion of IL-1 $\beta$ and IL-18 by inhibiting caspase-1 (20). An inhibitor of mammalian target of rapamycin (mTOR), rapamycin is widely used as an autophagy inducer (21). The induction of autophagy by rapamycin can suppress the production and secretion of IL-1 $\beta$ and IL-18 and limit excessive inflammation (21).

\section{IL-18 RECEPTOR AND SIGNAL TRANSDUCTION}

The IL-18 signaling pathway is illustrated in Figure 1. IL18 recognizes a heterodimeric receptor that consists of IL-18 receptor (R) $\alpha$ - and $\beta$-chains (22). IL-18R $\alpha$, also known as IL1 receptor-related protein (IL-1Rrp), binds specifically to the extracellular IL-18 at the cell surface. However, its affinity is low. IL-18R $\beta$ (i.e., accessory protein-like [AcPL]) is recruited to form a high affinity binding and activate intracellular signaling pathway $(23,24)$. IL-18R is expressed in most types of cells, including $\mathrm{T}$ cells, natural killer (NK) cells, macrophages, dendritic cells, neutrophils, basophils, mast cells, endothelial cells, and smooth muscle cells (25-32). The diversity of productive and receptorexpressing cells is linked to the functional diversity of IL-18.

Like IL-1R, IL-18R contains a Toll/IL-1 receptor (TIR) domain in the intracellular region that is shared with TLRs, and signaling into the cell is mediated by myeloid differentiation factor 88 (MyD88) (33-35). MyD88 is a well-known adaptor molecule for TLRs and IL-1R. The activation of IL-18R results in the recruitment of MyD88 to the TIR and anchors IL-1 receptorassociated kinase (IRAK) (36). Phosphorylated IRAK dissociates from the complex and binds to tumor necrosis factor receptorassociated factor 6 (TRAF6), which in turn phosphorylates nuclear factor kappa B (NF-кB)-induced kinase (NIK) (37). This results in the activation of I kappa $B$ (IкB) kinase (IKK). The phosphorylation of IKB by IKK leads to the ubiquitination and degradation of I $\mathrm{B}$ (38). NF- $\kappa \mathrm{B}$ is then able to migrate into the nucleus and initiate the transcription of target genes such as IFN- $\gamma(39)$.

Although the major signaling pathway of IL-18 is NF$\kappa \mathrm{B}$ signaling, it has been reported that stimulation by IL-18 strongly promotes the tyrosine phosphorylation of STAT3 and the mitogen-activated protein kinases (MAPKs) p44erk-1 and p42erk-2 in human NK cell lines (40). In murine T cells, IL18 induced the activation of the lymphocyte-specific tyrosine protein kinase p56lck and p42 MAPK (41).

\section{IL-18 BINDING PROTEIN}

As with IL-1, the activity of IL-18 is regulated by the endogenous inhibitor IL-18 binding protein (IL-18BP). IL-18BPa, the major splice variant of IL-18BP, is present in excess concentrations compared to IL-18 in the serum of healthy individuals and it binds with high affinity to IL-18 to neutralize its activity (42-44). IL-18BP inhibits the binding of IL-18 to the IL-18 receptor and inhibits the production of IFN- $\gamma$ (Figure 1). IFN- $\gamma$ has been reported to mediate the gene expression of IL-18BPa in nonleukocytic cells (45). IL-18 activity is regulated by a negative feedback mechanism mediated by IL-18BPa induced by IFN- $\gamma$. It is thus likely that IL-18BPa functions as a "shut off" signal to stop the excessive inflammatory response by IL-18 (44). The expression of IL-18BP is regulated mainly at the transcriptional level, and signal transducer and activator of transcription 1 (STAT1) and CCAAT/enhancer binding protein $\beta(\mathrm{C} / \mathrm{EBP} \beta)$ have been reported to be important transcription factors in the regulation of IL-18BP gene promoter activity $(46,47)$.

The activity of IL-18 is balanced by the presence of IL18BP. Serum IL-18BP levels are significantly elevated in sepsis and other inflammatory diseases $(42-44,48,49)$. Patients with granulomatosis with polyangiitis (i.e., Wegener's granulomatosis) and those with systemic lupus erythematosus showed elevated serum levels of IL-18 as well as IL-18BP, but the levels of IL-18BP were not sufficient to neutralize IL-18, and the levels of free IL-18 were higher than those of healthy subjects $(42,48)$.

Exogenous IL-18BP may be useful as a novel therapeutic agent for diseases involving IL-18 (42-44, 48, 49). A phase II clinical trial was conducted in patients with adult-onset Still's disease (50); the administration of tadekinig, a recombinant IL$18 \mathrm{BP}$, was observed to reduce the patients' serum C-reactive protein and ferritin levels and improve their clinical symptoms. A Phase III clinical trial of tadekinig is currently underway in patients suffering from pediatric monogenic auto-inflammatory diseases and harboring deleterious mutations of NLRC4 and XIAP (NCT03512314). 


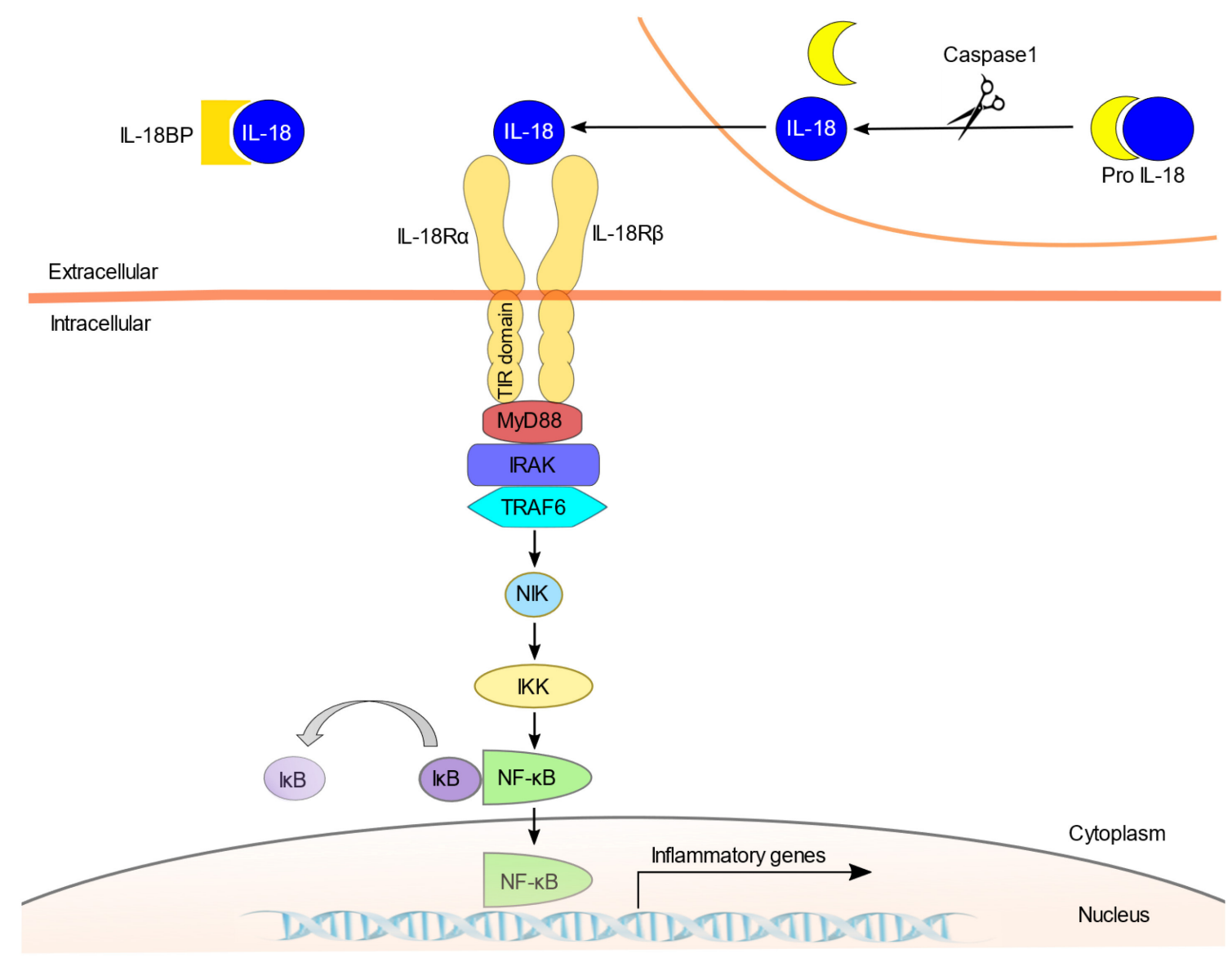

FIGURE 1 | The IL-18 signaling pathway. IL-18 is stored intracellularly as biologically inactive pro-IL-18 and is secreted extracellularly as the bioactive mature molecule after being cleaved by caspase-1. IL-18 is regulated by the endogenous inhibitor IL-18BP. Since IL-18BP has high affinity for IL-18, IL-18BP binds preferentially to IL-18 and inhibits binding to the IL-18R. IL-18 first binds to the IL-18R $\alpha$; however, this binding is low-affinity, and the IL-18R $\beta$ chain is recruited to form a high-affinity heterodimeric complex. The activation of IL-18R recruits MyD88 to the TIR domain and anchors IRAK. Phosphorylated IRAK activates TRAF6, and which in turn phosphorylates NIK. This is followed by the activation of IKK and finally NF-кB, which initiates the transcription of target genes such as IFN- $\gamma$.

\section{PHYSIOLOGICAL FUNCTIONS OF IL-18}

IL-18 was originally discovered as a factor that induces IFN- $\gamma$ from Th1 cells. The most important role of IL-18 in the immune system is the induction of the production of IFN- $\gamma$ by Th1 cells. IL-18 acts synergistically with IL-12 to induce a potent Th1 response (51-53), and IL-18 plays an important role in the host's defense mechanism against infections caused by pathogens such as bacteria, viruses, fungi, and protozoa (13). In concert with IL12 , IL-18 also induces the production of IFN- $\gamma$ by NK cells, B cells, and macrophages $(51,54,55)$. Although IL-18 induces IFN$\gamma$ production as a Th1 cytokine by co-stimulation with IL-12, IL-18 acts alone as a Th2 cytokine (13). Basophils and mast cells derived from bone marrow cells cultured with IL-3 for 10 days expressed IL-18R $\alpha$ (56). IL-3 is involved in the differentiation of mouse bone marrow cells into basophils and mast cells (57). Basophils produced both of the Th2 cytokines IL-4 and IL-13 in response to stimulation with IL-3 + IL-18 (56). Although mast cells did not produce IL-4, they produced IL-13 in response to stimulation with IL-3 + IL-18 (56). The administration of IL-18 together with IL-12 inhibits both the production of IgE and the productions of IL- 4 and IL-13 by basophils and mast cells in an IFN- $\gamma$-dependent manner (58). On the other hand, the administration of IL-18 alone has been reported to induce IgE production by B cells (59). IL-4 and IL-13 are involved in the production of IgE and the differentiation and proliferation of eosinophils and are important in the formation of allergic pathologies such as bronchial asthma and atopic dermatitis (60). These findings suggest that IL-18 may be involved in allergic inflammation.

In addition, IL-18 has been reported to up-regulate Fas ligand (FasL) expression in NK cells and induce apoptosis in Faspositive target cells $(61,62)$. In NK cells, IL-18 also enhances perforin-mediated cytotoxic activity (32). The activation of NK cells suggested that IL-18 may be associated with tumor immune responses $(13,63)$. It has been reported that treatment with IL-18 in combination with the B7-1 costimulatory molecule resulted in the regression of melanoma with increased NK 
TABLE 1 | IL-18 in renal disease models.

\begin{tabular}{llll}
\hline Disease Model & Intervention & Outcome & References \\
\hline AKI Model & & & \\
IRI & IL-18 BP & Protective & $(68)$ \\
IRI & IL-18-deficient & Protective & $(69)$ \\
LPS & IL-18R $\alpha$-deficient & Protective & $(70)$ \\
Cisplatin & Anti-IL-18 antibodies & Not protective & $(71)$ \\
Cisplatin & Overexpression of IL-18BP & Not protective & $(71)$ \\
Cisplatin & IL-18-deficient & Protective & $(72)$ \\
Cisplatin & IL-18R $\alpha$-deficient & Detrimental & $(73)$ \\
CKD Model & & & \\
Anti-GBM GN & IL-18-deficient & Protective & $(74)$ \\
Immune complex GN & IL-18R $\alpha$-deficient & Protective & $(75)$ \\
LN (MRL/pr) & IL-18 & Detrimental & $(76)$ \\
LN (MRL/pr) & IL-18R $\alpha$-deficient & Protective & $(77)$ \\
LN (MRL/pr) & IL-18-deficient & Protective & $(78)$ \\
LN (MRL/pr) & Anti-IL-18 autoantibodies & Protective & $(79)$ \\
UUO & (IL-18 vaccination) & & \\
UUO & Overexpression of IL-18BP & Protective & $(80)$ \\
\hline
\end{tabular}

IL, interleukin; IRI, ischemia-reperfusion injury; $B P$, binding protein; LPS, lipopolysaccharide; GBM, glomerular basement membrane; GN, glomerulonephritis; LN, lupus nephritis; UUO, unilateral ureteral obstruction.

cell infiltration at the tumor tissue (64). In addition to the above-described activities, IL-18 induces the production of granulocyte/macrophage colony-stimulating factor (GM-CSF) and the expression of adhesion molecules. In co-culture with osteoblasts and hematopoietic cells, IL-18 inhibited the formation of osteoclastlike cells via the production of GM-CSF (65). IL-18 enhanced the expression of intercellular adhesion molecule-1 (ICAM-1) in human myelomonocytic cell lines (66), and ICAM-1 and vascular cell adhesion molecule-1 (VCAM-1) in endothelial cells and rheumatoid arthritis synovial fibroblasts (67). As described above, IL-18 has various pro-inflammatory effects besides the induction of IFN- $\gamma$ production, and IL-18 may be associated with various pathologies such as infections, allergic diseases, and tumor immunity.

\section{IL-18 AND INFLAMMATORY KIDNEY DISEASE}

Inflammation underlies the pathogenesis of many renal diseases, including acute kidney injury (AKI) and chronic kidney disease (CKD), and the role of IL-18 in inflammation has been reported in many experimental animal models (summarized in Table 1). In clinical practice, IL-18 is expected to be useful in the diagnosis of diseases and the estimation of disease severity and prognosis.

\section{IL-18 as a Biomarker for AKI}

Urinary IL-18 has been reported to be increased in patients with acute tubular necrosis after kidney transplantation $(82,83)$. The urinary level of IL-18 is expected to be an early diagnostic marker of acute kidney injury (AKI), and many clinical trials have been conducted. A meta-analysis summarizing reports after cardiac surgery showed that the sensitivity and specificity values of urinary IL-18 as a biomarker for the diagnosis of AKI were 0.58 and 0.75 , respectively (84). The area under the receiver operating characteristic curve (AUROC) of urinary IL-18 levels predictive of AKI was 0.70 (84). In another meta-analysis, the AUROC was similar at 0.77 (85). Urinary IL-18 is a biomarker of AKI with moderate diagnostic value. Although it does not reliably predict the development of AKI, urinary IL-18 has been reported to be useful to predict clinical outcomes including mortality and dialysis in a heterogeneous intensive care unit (ICU) population (86).

It has been reported that urinary IL-18 levels in patients with AKI after cardiopulmonary bypass increased over the first 4-6h, peaked in $12 \mathrm{~h}$, and remained elevated up to $48 \mathrm{~h}$ after surgery $(87,88)$. This elevation of urinary IL-18 in AKI is slower than that observed in urinary neutrophil gelatinase-associated lipocalin $(87,88)$. The urinary IL-18 level in patients with acute tubular necrosis has been shown to be significantly elevated compared to patients with urinary tract infections, pre-renal acute renal failure, chronic kidney disease, and nephrotic syndrome (82). However, because urinary IL-18 is also elevated in septic patients $(86,89)$, caution should be exercised when using the urinary IL-18 level for the diagnosis of AKI.

\section{Ischemic Renal Disease}

Ischemia-reperfusion injury (IRI) in the kidney is used as a model of AKI. An AKI caused as a result of IRI involves both innate and acquired immune responses (90). In an IRI mouse model, the plasma and renal IL-18 levels were shown to be significantly increased after IRI stress $(68,69)$. Compared to wildtype mice, IL-18-deficient mice were protected from IRI and showed better renal function, less tubular damage, less neutrophil and macrophage infiltration, and less expression of downstream inflammatory mediators of IL-18 (69). In a mouse model of IRI, treatment with IL-18BP, an IL-18 inhibitor, showed a renalprotective effect (69). Treatment with IL-18 BP has also been shown to reduce the levels of profibrotic molecules in the kidneys of mice after IRI and to inhibit the progression of IRI-induced renal fibrosis (68). Because caspase-1 activates IL-18, caspase1 -deficient mice are also protected against ischemic acute renal failure (15). Although IL-18 is produced by various types of cells, it has been reported that cells of bone marrow origin play a more important role than intrinsic kidney cells in the renal damage caused by IRI (69). Blocking IL-18 signaling may be protective against IRI-induced AKI.

\section{LPS-Induced AKI}

We reported the role of IL-18 in LPS-induced AKI in IL-18R $\alpha$ deficient mice (70). In CD4 $+\mathrm{T}$ cells derived from splenocytes, the mRNA expressions of IL-18 and IL-18R $\alpha$ were significantly increased after LPS injection. The IL-18R $\alpha$-deficient mice showed lower blood urea nitrogen (BUN) levels, a higher survival rate, and reduced levels of pro-inflammatory cytokines such as IL18 and IFN- $\gamma$ compared to wild-type mice. Glomerular CD4+ $\mathrm{T}$ cells and interstitial macrophage infiltration were reduced in the kidneys of the IL-18R $\alpha$-deficient mice. IL-18R-mediated 
signaling pathways may plays critical roles in these cells in the pathogenesis of LPS-induced AKI.

\section{Cisplatin-Induced AKI}

In vitro, cisplatin induces the apoptosis or necrosis of renal tubules (91). Cisplatin administration increases serum and renal levels of IL-18 (71). However, methods to inhibit IL-18 using IL-18 antiserum or transgenic mice that overproduce IL-18BP did not protect against cisplatin-induced AKI (71). On the other hand, IL-18-deficient mice have been reported to be protected from AKI, and the exogenous supplementation of recombinant IL-18 prior to cisplatin administration caused AKI (72). In our study using IL-18R $\alpha$-deficient mice, the inhibition of IL18 signaling did not result in a favorable effect. We observed that compared to wild-type mice, the IL-18R $\alpha$-deficient mice had worse renal function and downregulated expressions of suppressor of cytokine signaling (SOCS) 1 and SOCS3 in the spleen and kidney (73). The inhibition of cytokine signaling by the members of the SOCS family constitutes a major negative feedback mechanism to prevent runaway inflammation. SOCS1 reduces the impact of cytokines by inhibiting JAK kinases and several other mechanisms (92). Although the mechanism is not clear, we speculate that IL-18R $\alpha$ may induce an antiinflammatory response by affecting the expressions of the cytokine signaling inhibitors SOCS1 and SOCS3 in addition to the inflammatory response. In summary, the inhibition of IL18 may not be sufficient for the prevention of cisplatin-induced AKI. The effect of IL-18 on cisplatin-induced AKI appears to vary between mouse models, and further research is needed.

\section{Glomerulonephritis}

Neutrophils play an important role in the pathogenesis of antineutrophil cytoplasmic antibody (ANCA)-associated vasculitis (AAV). Neutrophils require priming for subsequent ANCA-induced activation, and IL-18 is thought to be important for neutrophil priming in AAV, as is tumor necrosis factor-alpha (TNF- $\alpha)(93,94)$. In vitro, IL-18 can prime neutrophils, and it enhances superoxide production by cells after ANCA binding $(93,94)$. AAV patients have higher serum IL-18 concentrations compared to healthy controls (95). In renal biopsies from AAV patients, IL-18-positive cells were found in podocytes in the glomerulus and in myofibroblasts, distal tubular epithelial cells, and infiltrating macrophages in the interstitium (94).

In patients with IgA nephropathy, serum IL-18 levels have been reported to correlate significantly with urinary protein excretion, serum creatinine, and the estimated glomerular filtration rate (eGFR) (96). In addition, patients with high IL-18 levels at baseline were shown to have worse renal function during the follow-up period (96). The serum IL-18 level may predict the reduction of renal function in patients with IgA nephropathy. In renal biopsies of IgA nephropathy patients, the expression levels of IL-18 were positively correlated with both the infiltration of inflammatory cells into the interstitium and the extent of proteinuria (74).
A role of IL-18 has been reported in several experimental animal models of glomerulonephritis. In a model of antiglomerular basement membrane nephritis in mice, IL-18deficient mice had reduced leukocyte infiltration in the glomeruli and interstitium (97). Based on our findings obtained with a bovine serum albumin glomerulonephritis mouse model, we reported that IL-18R $\alpha$-deficient mice showed a significant reduction of proteinuria, renal pathological findings including glomerular IgG and C3 deposits, and leukocyte infiltrates compared to control mice (75). Thus, in experiments with several animal models, the suppression of IL-18 signaling has been shown to be protective against glomerulonephritis.

\section{Lupus Nephritis}

Lupus nephritis (LN) is a frequent and severe organ lesion associated with systemic lupus erythematosus (SLE) (98). IL-18 has been implicated in the pathogenesis of SLE, based on studies in mice and humans. MRL/lpr mice, which develop spontaneous lupus-like autoimmune disease, had higher levels of serum IL18 compared to controls (76), and the mice treated with IL18 developed accelerated proteinuria, glomerulonephritis and vasculitis (76). We reported that IL-18R $\alpha$-deficient MRL/lpr mice survived longer than IL-18 $\alpha$-intact MRL/lpr mice, and we observed significant reductions in glomerular IgG deposition, proteinuria, and serum anti-DNA antibodies in the IL-18R $\alpha$ deficient MRL/lpr mice (77). Similarly, some other groups have reported improved survival and proteinuria in IL-18-deficient and IL-18-vaccinated MRL/lpr mice $(78,79)$.

High serum IL-18 levels have been reported in patients with SLE $(99,100)$. Patients with active renal disease also have higher serum levels of IL-18 than those without renal activity $(99,100)$. It was reported that in the serum of LN patients, not only IL18 but also IL-18BP, which neutralizes the activity of IL-18, are significantly increased, but the IL-18/IL-18BP ratio is also increased (101). This imbalance between IL-18 and IL-18BP may be involved in the pathogenesis of LN (101).

Serum IL-18 levels correlate with the disease activity of SLE $(99,100,102)$ and are also associated with the severity of LN $(100,103,104)$. Several studies indicated that the IL-18 value in the serum or glomeruli of patients with class IV LN was increased compared to the LN class III and V patients. Thus, IL-18 may be useful for the identification of LN in SLE patients and for estimating the severity of LN.

\section{Diabetic Nephropathy}

Inflammatory cytokines play an important role in the development and progression of diabetic nephropathy (105). In clinical studies, elevated plasma and urinary IL-18 levels were associated with diabetic nephropathy, and IL-18 was observed to be a predictive marker for the development of diabetic nephropathy in diabetic patients and to be associated with the progression of renal dysfunction (106-108). Serum and urinary IL-18 levels correlate with the degree of urinary albumin excretion $(107,108)$. Elevated serum and urinary IL-18 levels in diabetic patients may be a risk factor for the development of diabetic nephropathy. In kidney tissue of diabetic nephropathy patients, IL-18 is overexpressed in tubular epithelial cells, which 
may occur via the activation of the MAPK pathways induced by transforming growth factor-beta (TGF- $\beta$ ) (109). Treatment that blocks IL-18 signaling may be a new approach in the treatment of diabetic nephropathy.

\section{Obstructive Nephropathy}

Renal interstitial fibrosis is a common and important lesion in the process of various progressive renal diseases that progress to renal atrophy. Unilateral ureteral obstruction (UUO) is an important model for studying the mechanisms of renal fibrosis and evaluating the potential therapeutic approaches (110). In UUO model mice, it was reported that serum IL-18 levels were elevated and the renal IL-18 and IL-18R expressions were enhanced after a UUO operation $(16,17,80,81)$. We reported that compared to wild-type mice, IL-18R $\alpha$-deficient mice had reduced tubular cell apoptosis and suppressed renal interstitial fibrosis after UUO (81). Similarly, transgenic mice with neutralized IL-18 activity also show reduced fibrosis (80).

In general, TGF- $\beta$ is a mediator that plays a central role in renal fibrosis (111). Interestingly, in our previous study, there was no significant difference in the expression of renal TGF- $\beta$ between IL-18R $\alpha$-deficient and wild-type mice (81). IL-18 may be involved in renal interstitial fibrosis by a mechanism that is independent of TGF- $\beta(80,81)$. In vitro, FasL expression in human proximal tubular cells has been reported to be enhanced by IL-18 exposure, and IL-18 may stimulate proapoptotic signaling through a FasL-dependent mechanism and affect obstructive nephropathy (112). In addition, TLR4 signaling may affect IL-18-mediated profibrotic effects $(113,114)$. Experiments using these mouse models suggested that (i) IL-18 signaling plays an important role in renal interstitial fibrosis during renal obstruction, and (ii) the inhibition of IL-18 acts protectively against fibrosis.

\section{COVID-19}

COVID-19, caused by severe acute respiratory syndrome coronavirus 2 (SARS-CoV-2) and first detected in the city of Wuhan in China's Hubei Province, has become a global pandemic. In response to SARS-CoV-2 infection, the human body produces pro-inflammatory cytokines such as IL-1 $\beta$, IL-6, IL-7, IL-8, TNF- $\alpha$, granulocyte-colony stimulating factor (G-CSF), interferon gamma-induced protein 10 (IP-10), monocyte chemotactic protein (MCP)-1, and MCP-3 (115-117). COVID-19 produces an excessive inflammation "cytokine storm" that leads to acute respiratory distress syndrome (ARDS) and the failure of multiple organs including kidney.

The incidence of AKI in COVID-19 patients is higher than that in non-COVID-19 patients, and AKI associated with COVID-19 has been shown to be independently associated with an almost 4-fold higher odds of death than AKI associated with other acute illnesses (118). However, in general, critically ill patients with ARDS and AKI have many complications that can induce acute tubulointerstitial injury, and the causal relationship between coronavirus infection and AKI remains unclear. Factors that may contribute to the development of AKI in COVID-19 patients include direct viral infections, the cytokine storm, drug treatments, hemodynamic instability, and advancing hypercoagulable state. In a renal histological analysis of samples from autopsies of 26 patients who died of COVID-19-induced respiratory failure, clinical signs of renal injury, including increased serum creatinine and/or new-onset proteinuria, were observed in only nine of the 26 patients (34.6\%), while mild to severe acute tubular injury was observed in all 26 patients (119). Three patients had pigmented tubular casts, three had segmental glomerular fibrin thrombi and two had focal segmental glomerulosclerosis. In seven patients, electron microscopy showed coronavirus-like particles in the tubular epithelium and podocytes. The SARS-CoV-2 virus uses angiotensin-converting enzyme 2 (ACE2) as a receptor for host cell entry. In the kidney, ACE2 is predominantly expressed in proximal tubules and is also present in podocytes and endothelial and smooth muscle cells of vessels (120). The finding that SARS-CoV-2 infects these cells (119) may indicate that the virus causes renal injury directly. However, it has been reported that multivesicular bodies (MVBs) mimicking SARS-CoV-2 are found in podocytes of COVID-19-negative patients, and it has not yet been established whether SARS-CoV-2 truly causes direct kidney injury (121).

Many cytokines are involved in the pathogenesis of COVID-19, and IL-18 may also be relevant (122, 123). Serum IL-18 levels have been shown to correlate with serum IL-6 levels, with inflammatory markers such as C-reactive protein and ferritin, and with markers of organ injury such as creatinine, liver enzymes, and troponin (122). It has also been reported that serum IL-18 levels on admission are higher in COVID-19 patients requiring mechanical ventilation and lethal cases (123). IL-18 may be related to the severity of COVID19. The appropriate control of pro-inflammatory cytokines, including IL-18, may be a therapeutic option for managing the complications caused by the cytokine storm in COVID-19. There are currently no clinical trials examining IL-18 signaling. On the other hand, the effect of the humanized anti-IL-6 receptor antibody tocilizumab on COVID-19 has been reported. Several open-label trials and non-randomized case series reported positive effects of tocilizumab on COVID-19 (124); however, phase III clinical trials did not show efficacy of tocilizumab for preventing intubation or death in moderately ill hospitalized patients with COVID-19 (125). Although the regulation of IL-18 signaling may be a potential therapeutic target for COVID-19, the suppression of IL-18 signaling alone may not be sufficient to control the disease, as many cytokines are involved in the severity of COVID-19.

\section{CONCLUSION}

IL-18 belongs to the IL-1 superfamily and drives the same MyD88/NF- $\kappa$ B signaling pathway as IL- $1 \beta$. IL-18 is a proinflammatory cytokine that induces IFN- $\gamma$ production and has a variety of other functions, including the enhancement of NK cell activity and up-regulation of FasL expression. IL18 appears to regulate inflammation at multiple checkpoints. Pre-clinical and clinical studies have obtained interesting results in many circumstances in which IL-18 is associated with an increased inflammatory infiltrate and more severe kidney lesions. 
These results suggest that IL-18 may play an important role in the pathology of inflammatory kidney diseases, and they raise expectations that IL-18 may be a potential therapeutic target. However, there is a lack of clinical studies targeting IL-18 in inflammatory renal disease. In addition, the role and signaling of IL-18 in inflammatory kidney disease are not fully understood. It remains unknown whether IL-18 is clearly implicated in disease pathogeneses. In experimental animal models, IL-18-deficiency, anti-IL-18 antibodies, IL-18Rdeficiency, and IL-18BP all regulate IL-18 signaling, and in many cases their effects are protective for the kidneys. Some conflicting

\section{REFERENCES}

1. Medzhitov R. Origin and physiological roles of inflammation. Nature. (2008) 454:428-35. doi: 10.1038/nature07201

2. Martinon F, Burns K, Tschopp J. The inflammasome: a molecular platform triggering activation of inflammatory caspases and processing of proIL- $\beta$. Mol Cell. (2002) 10:417-26. doi: 10.1016/S1097-2765(02)00599-3

3. Strowig T, Henao-Mejia J, Elinav E, Flavell R. Inflammasomes in health and disease. Nature. (2012) 481:278-86. doi: 10.1038/nature10759

4. Davis BK, Wen H, Ting JP. The inflammasome NLRs in immunity, inflammation, and associated diseases. Annu Rev Immunol. (2011) 29:70735. doi: 10.1146/annurev-immunol-031210-101405

5. Anders HJ, Muruve DA. The inflammasomes in kidney disease. J Am Soc Nephrol. (2011) 22:1007-18. doi: 10.1681/ASN.2010080798

6. Mantovani A, Dinarello CA, Molgora M, Garlanda C. IL-1 and related cytokines in innate and adaptive immunity in health and disease. Immunity. (2019) 50:778-95. doi: 10.1016/j.immuni.2019.03.012

7. Gracie JA, Robertson SE, Mcinnes IB. Interleukin-18. J Leukoc Biol. (2003) 73:213-24. doi: $10.1189 / \mathrm{jlb} .0602313$

8. Akira S. The role of IL-18 in innate immunity. Curr Opin Immunol. (2000) 12:59-63. doi: 10.1016/S0952-7915(99)00051-5

9. Okamura H, Tsutsi H, Komatsu T, Yutsudo M, Hakura A, Tanimoto T, et al. Cloning of a new cytokine that induces IFN-gamma production by $\mathrm{T}$ cells. Nature. (1995) 378:88-91. doi: 10.1038/378088a0

10. Okamura H, Nagata K, Komatsu T, Tanimoto T, Nukata Y, Tanabe F, et al. A novel costimulatory factor for gamma interferon induction found in the livers of mice causes endotoxic shock. Infect Immun. (1995) 63:3966-72. doi: 10.1128/IAI.63.10.3966-3972.1995

11. Nakamura K, Okamura H, Nagata $K$, Komatsu T, Tamura $T$. Purification of a factor which provides a costimulatory signal for gamma interferon production. Infect Immun. (1993) 61:64-70. doi: 10.1128/IAI.61.1.64-70.1993

12. Kato Z, Jee J, Shikano H, Mishima M, Ohki I, Ohnishi H, et al. The structure and binding mode of interleukin-18. Nat Struct Biol. (2003) 10:966-71. doi: 10.1038/nsb993

13. Nakanishi $\mathrm{K}$, Yoshimoto T, Tsutsui H, Okamura H. Interleukin-18 regulates both Th1 and Th2 responses. Annu Rev Immunol. (2001) 19:423-74. doi: 10.1146/annurev.immunol.19.1.423

14. Dinarello CA. Interleukin 1 and interleukin 18 as mediators of inflammation and the aging process. Am J Clin Nutr. (2006) 83:447S-55S. doi: 10.1093/ajen/83.2.447S

15. Melnikov VY, Ecder T, Fantuzzi G, Siegmund B, Lucia MS, Dinarello $\mathrm{CA}$, et al. Impaired IL-18 processing protects caspase-1-deficient mice from ischemic acute renal failure. J Clin Invest. (2001) 107:1145-52. doi: 10.1172/JCI12089

16. Franke EI, Vanderbrink BA, Hile KL, Zhang H, Cain A, Matsui F, et al. Renal IL-18 production is macrophage independent during obstructive injury. PLoS ONE. (2012) 7:e47417. doi: 10.1371/journal.pone.0047417

17. Vanderbrink BA, Asanuma H, Hile K, Zhang H, Rink RC, Meldrum KK. Interleukin-18 stimulates a positive feedback loop during renal obstruction via interleukin-18 receptor. J Urol. (2011) 186:1502-8. doi: 10.1016/j.juro.2011.05.046 results suggest that their respective signaling pathways, effects on cytokines, etc. may not be identical. Studies that will further elucidate IL-18 signaling are important for understanding the pathogenesis of inflammatory kidney disease and for therapeutic applications.

\section{AUTHOR CONTRIBUTIONS}

YH drafted the manuscript. YN edited the manuscript. Both authors contributed to the manuscript's revision and have read and approved the submitted version.

18. Chandrasekar B, Colston JT, de la Rosa SD, Rao PP, Freeman GL. TNF-alpha and $\mathrm{H}_{2} \mathrm{O}_{2}$ induce IL-18 and IL-18R beta expression in cardiomyocytes via NF-kappa B activation. Biochem Biophys Res Commun. (2003) 303:1152-8. doi: 10.1016/S0006-291X(03)00496-0

19. Suk K, Yeou Kim S, Kim H. Regulation of IL-18 production by IFN gamma and PGE2 in mouse microglial cells: involvement of NF-kB pathway in the regulatory processes. Immunol Lett. (2001) 77:79-85. doi: 10.1016/S0165-2478(01)00209-7

20. Kim YM, Talanian RV, Li J, Billiar TR. Nitric oxide prevents IL-1beta and IFN-gamma-inducing factor (IL-18) release from macrophages by inhibiting caspase-1 (IL-1beta-converting enzyme). J Immunol. (1998) 161:4122-8.

21. Jia X, Cao B, An Y, Zhang X, Wang C. Rapamycin ameliorates lipopolysaccharide-induced acute lung injury by inhibiting IL-1beta and IL-18 production. Int Immunopharmacol. (2019) 67:211-9. doi: 10.1016/j.intimp.2018.12.017

22. Hoshino K, Tsutsui H, Kawai T, Takeda K, Nakanishi K, Takeda Y, et al. Cutting edge: generation of IL-18 receptor-deficient mice: evidence for IL1 receptor-related protein as an essential IL-18 binding receptor. J Immunol. (1999) 162:5041-4.

23. Torigoe K, Ushio S, Okura T, Kobayashi S, Taniai M, Kunikata T, et al. Purification and characterization of the human interleukin-18 receptor. J Biol Chem. (1997) 272:25737-42. doi: 10.1074/jbc.272.41.25737

24. Born TL, Thomassen E, Bird TA, Sims JE. Cloning of a novel receptor subunit, AcPL, required for interleukin-18 signaling. J Biol Chem. (1998) 273:29445-50. doi: 10.1074/jbc.273.45.29445

25. Nakamura S, Otani T, Okura R, Ijiri Y, Motoda R, Kurimoto M, et al. Expression and responsiveness of human interleukin-18 receptor (IL-18R) on hematopoietic cell lines. Leukemia. (2000) 14:1052-9. doi: 10.1038/sj.leu.2401789

26. Chan WL, Pejnovic N, Lee CA, Al-Ali NA. Human IL-18 receptor and ST2L are stable and selective markers for the respective type 1 and type 2 circulating lymphocytes. I Immunol. (2001) 167:1238-44. doi: 10.4049/jimmunol.167.3.1238

27. Airoldi I, Gri G, Marshall JD, Corcione A, Facchetti P, Guglielmino R, et al. Expression and function of IL-12 and IL-18 receptors on human tonsillar B cells. J Immunol. (2000) 165:6880-8. doi: 10.4049/jimmunol.165.12.6880

28. Gracie JA, Forsey RJ, Chan WL, Gilmour A, Leung BP, Greer MR, et al. A proinflammatory role for IL-18 in rheumatoid arthritis. J Clin Invest. (1999) 104:1393-401. doi: 10.1172/JCI7317

29. Gutzmer R, Langer K, Mommert S, Wittmann M, Kapp A, Werfel T. Human dendritic cells express the IL-18R and are chemoattracted to IL-18. J Immunol. (2003) 171:6363-71. doi: 10.4049/jimmunol.171.12.6363

30. Wang Z, Liu Z, Wang L, Wang J, Chen L, Xie H, et al. Altered expression of IL-18 binding protein and IL-18 receptor in basophils and mast cells of asthma patients. Scand J Immunol. (2018) 87:e12658. doi: 10.1111/sji.12658

31. Leung BP, Culshaw S, Gracie JA, Hunter D, Canetti CA, Campbell C, et al. A role for IL-18 in neutrophil activation. J Immunol. (2001) 167:2879-86. doi: 10.4049/jimmunol.167.5.2879

32. Hyodo Y, Matsui K, Hayashi N, Tsutsui H, Kashiwamura S, Yamauchi H, et al. IL-18 up-regulates perforin-mediated NK activity without increasing perforin messenger RNA expression by binding to constitutively expressed IL-18 receptor. J Immunol. (1999) 162:1662-8. 
33. Kawai T, Akira S. Toll-like receptors and their crosstalk with other innate receptors in infection and immunity. Immunity. (2011) 34:637-50. doi: 10.1016/j.immuni.2011.05.006

34. Takeuchi O, Akira S. Pattern recognition receptors and inflammation. Cell. (2010) 140:805-20. doi: 10.1016/j.cell.2010.01.022

35. Adachi O, Kawai T, Takeda K, Matsumoto M, Tsutsui H, Sakagami $\mathrm{M}$, et al. Targeted disruption of the MyD88 gene results in loss of IL-1- and IL- 18-mediated function. Immunity. (1998) 9:143-50. doi: 10.1016/S1074-7613(00)80596-8

36. Kanakaraj P, Ngo K, Wu Y, Angulo A, Ghazal P, Harris CA, et al. Defective interleukin (IL)-18-mediated natural killer and Thelper cell type 1 responses in IL-1 receptor-associated kinase (IRAK)-deficient mice. J Exp Med. (1999) 189:1129-38. doi: 10.1084/jem.189.7.1129

37. Kojima H, Takeuchi M, Ohta T, Nishida Y, Arai N, Ikeda M, et al. Interleukin18 activates the IRAK-TRAF6 pathway in mouse EL-4 cells. Biochem Biophys Res Commun. (1998) 244:183-6. doi: 10.1006/bbrc.1998.8236

38. Sedimbi SK, Hägglöf T, Karlsson MC. IL-18 in inflammatory and autoimmune disease. Cell Mol Life Sci. (2013) 70:4795-808. doi: 10.1007/s00018-013-1425-y

39. Matsumoto S, Tsuji-Takayama K, Aizawa Y, Koide K, Takeuchi M, Ohta T, et al. Interleukin-18 activates NF- $\kappa \mathrm{B}$ in murine T helper type 1 cells. Biochem Biophys Res Commun. (1997) 234:454-7. doi: 10.1006/bbrc.1997.6665

40. Kalina U, Kauschat D, Koyama N, Nuernberger H, Ballas K, Koschmieder S, et al. IL-18 activates STAT3 in the natural killer cell line 92, augments cytotoxic activity, and mediates IFN- $\gamma$ production by the stress kinase p38 and by the extracellular regulated kinases p44erk-1 and p42erk-21. $J$ Immunol. (2000) 165:1307-13. doi: 10.4049/jimmunol.165.3.1307

41. Tsuji-Takayama K, Matsumoto S, Koide K, Takeuchi M, Ikeda M, Ohta T, et al. Interleukin-18 induces activation and association of p56lck and MAPK in murine TH1 clone. Biochem Biophys Res Commun. (1997) 237:126-30. doi: 10.1006/bbrc.1997.7099

42. Novick D, Elbirt D, Miller G, Dinarello CA, Rubinstein M, Sthoeger ZM. High circulating levels of free interleukin-18 in patients with active SLE in the presence of elevated levels of interleukin-18 binding protein. J Autoimmun. (2010) 34:121-6. doi: 10.1016/j.jaut.2009.08.002

43. Girard C, Rech J, Brown M, Allali D, Roux-Lombard P, Spertini F, et al. Elevated serum levels of free interleukin-18 in adult-onset Still's disease. Rheumatology. (2016) 55:2237-47. doi: 10.1093/rheumatology/kew300

44. Novick D, Schwartsburd B, Pinkus R, Suissa D, Belzer I, Sthoeger $\mathrm{Z}$, et al. A novel IL-18BP ELISA shows elevated serum IL-18BP in sepsis and extensive decrease of free IL-18. Cytokine. (2001) 14:334-42. doi: 10.1006/cyto.2001.0914

45. Mühl H, Kämpfer H, Bosmann M, Frank S, Radeke H, Pfeilschifter J. Interferon-gamma mediates gene expression of IL-18 binding protein in nonleukocytic cells. Biochem Biophys Res Commun. (2000) 267:960-3. doi: 10.1006/bbrc. 1999.2064

46. Hurgin V, Novick D, Rubinstein M. The promoter of IL-18 binding protein: activation by an IFN-gamma -induced complex of IFN regulatory factor 1 and CCAAT/enhancer binding protein beta. Proc Natl Acad Sci USA. (2002) 99:16957-62. doi: 10.1073/pnas.262663399

47. Bachmann M, Paulukat J, Pfeilschifter J, Mühl H. Molecular mechanisms of IL-18BP regulation in DLD-1 cells: pivotal direct action of the STAT1/GAS axis on the promoter level. J Cell Mol Med. (2009) 13:1987-94. doi: 10.1111/j.1582-4934.2008.00604.x

48. Novick D, Elbirt D, Dinarello CA, Rubinstein M, Sthoeger ZM. Interleukin18 binding protein in the sera of patients with Wegener's granulomatosis. $J$ Clin Immunol. (2009) 29:38-45. doi: 10.1007/s10875-008-9217-0

49. Mazodier K, Marin V, Novick D, Farnarier C, Robitail S, Schleinitz $\mathrm{N}$, et al. Severe imbalance of IL-18/IL-18BP in patients with secondary hemophagocytic syndrome. Blood. (2005) 106:3483-9. doi: 10.1182/blood-2005-05-1980

50. Gabay C, Fautrel B, Rech J, Spertini F, Feist E, Kötter I, et al. Open-label, multicentre, dose-escalating phase II clinical trial on the safety and efficacy of tadekinig alfa (IL-18BP) in adult-onset Still's disease. Ann Rheum Dis. (2018) 77:840-7. doi: 10.1136/annrheumdis-2017-212608

51. Yoshimoto T, Takeda K, Tanaka T, Ohkusu K, Kashiwamura S, Okamura $\mathrm{H}$, et al. IL-12 up-regulates IL-18 receptor expression on T cells, Th1 cells, and B cells: Synergism with IL-18 for IFN-gamma production. J Immunol. (1998) 161:3400-7.

52. Ahn HJ, Maruo S, Tomura M, Mu J, Hamaoka T, Nakanishi K, et al. A mechanism underlying synergy between IL-12 and IFN-gamma-inducing factor in enhanced production of IFN-gamma. J Immunol. (1997) 159:212531.

53. Tominaga K, Yoshimoto T, Torigoe K, Kurlmoto M, Matsui K, Hada T, et al. IL-12 synergizes with IL-18 or IL- $1 \beta$ for IFN- $\gamma$ production from human T cells. Int Immunol. (2000) 12:151-60. doi: 10.1093/intimm/12.2.151

54. Tomura M, Zhou XY, Maruo S, Ahn HJ, Hamaoka T, Okamura H, et al. A critical role for IL-18 in the proliferation and activation of NK1.1+ CD3cells. J Immunol. (1998) 160:4738-46.

55. Munder BM, Mallo M, Eichmann K, Modolell M. Murine macrophages secrete interferon gamma upon combined stimulation with interleukin (IL)12 and IL-18: a novel pathway of autocrine macrophage activation. J Exp Med. (1998) 187:2103-8. doi: 10.1084/jem.187.12.2103

56. Yoshimoto T, Tsutsui H, Tominaga K, Hoshino K, Okamura H, Akira S, et al. IL-18, although antiallergic when administered with IL-12, stimulates IL-4 and histamine release by basophils. Proc Natl Acad Sci USA. (1999) 96:13962-6. doi: 10.1073/pnas.96.24.13962

57. Reinhart R, Rohner L, Wicki S, Fux M, Kaufmann T. BH3 mimetics efficiently induce apoptosis in mouse basophils and mast cells. Cell Death Differ. (2018) 25:204-16. doi: 10.1038/cdd.2017.154

58. Yoshimoto T, Okamura H, Tagawa YI, Iwakura Y, Nakanishi K. Interleukin 18 together with interleukin 12 inhibits IgE production by induction of interferon- $\gamma$ production from activated B cells. Proc Natl Acad Sci USA. (1997) 94:3948-53. doi: 10.1073/pnas.94.8.3948

59. Yoshimoto T, Mizutani H, Tsutsui H, Noben-Trauth N, Yamanaka KI, Tanaka M, et al. IL-18 induction of IgE: dependence on CD4+ T cells, IL-4 and STAT6. Nat Immunol. (2000) 1:132-7. doi: 10.1038/77811

60. Wills-Karp M. Immunologic basis of antigen-induced airway hyperresponsiveness. Annu Rev Immunol. (1999) 17:255-81. doi: 10.1146/annurev.immunol.17.1.255

61. Tsutsui H, Nakanishi K, Matsui K, Higashino K, Okamura H, Miyazawa $\mathrm{Y}$, et al. IFN-gamma-inducing factor up-regulates Fas ligand-mediated cytotoxic activity of murine natural killer cell clones. J Immunol. (1996) 157:3967-73.

62. Ohtsuki T, Micallef MJ, Kohno K, Tanimoto T, Ikeda M, Kurimoto M. Interleukin 18 enhances Fas ligand expression and induces apoptosis in Fas-expressing human myelomonocytic KG-1 cells. Anticancer Res. (1997) 17:3253-58.

63. Baker KJ, Houston A, Brint E. IL-1 family members in cancer; two sides to every story. Front Immunol. (2019) 10:1197. doi: 10.3389/fimmu.2019.01197

64. Cho D, Kim TG, Lee W, Hwang YI, Cho HI, Han H, et al. Interleukin18 and the costimulatory molecule B7-1 have a synergistic anti-tumor effect on murine melanoma; implication of combined immunotherapy for poorly immunogenic malignancy. J Invest Dermatol. (2000) 114:928-34. doi: 10.1038/sj.jid.5600685

65. Udagawa N, Horwood NJ, Elliott J, Mackay A, Owens J, Okamura H, et al. Interleukin-18 (interferon- $\gamma$-inducing factor) is produced by osteoblasts and acts via granulocyte/macrophage colony-stimulating factor and not via interferon- $\gamma$ to inhibit osteoclast formation. J Exp Med. (1997) 185:1005-012. doi: 10.1084/jem.185.6.1005

66. Kohka H, Yoshino T, Iwagaki H, Sakuma I, Tanimoto T, Matsuo Y, et al. Interleukin-18/interferon- $\gamma$-inducing factor, a novel cytokine, up-regulates ICAM-1 (CD54) expression in KG-1 cells. J Leukoc Biol. (1998) 64:519-27. doi: 10.1002/jlb.64.4.519

67. Morel JCM, Park CC, Woods JM, Koch AE. A novel role for interleukin18 in adhesion molecule induction through NFKB and phosphatidylinositol (PI) 3-kinase-dependent signal transduction pathways. J Biol Chem. (2001) 276:37069-75. doi: 10.1074/jbc.M103574200

68. Liang H, Xu F, Zhang T, Huang J, Guan Q, Wang H, et al. Inhibition of IL18 reduces renal fibrosis after ischemia-reperfusion. Biomed Pharmacother. (2018) 106:879-89. doi: 10.1016/j.biopha.2018.07.031

69. Wu H, Craft ML, Wang P, Wyburn KR, Chen G, Ma J, et al. IL-18 contributes to renal damage after ischemia-reperfusion. J Am Soc Nephrol. (2008) 19:2331-41. doi: 10.1681/ASN.2008020170 
70. Nozaki Y, Hino S, Ri J, Sakai K, Nagare Y, Kawanishi M, et al. Lipopolysaccharide-induced acute kidney injury is dependent on an il-18 receptor signaling pathway. Int J Mol Sci. (2017) 18:2777. doi: $10.3390 /$ ijms 18122777

71. Faubel S, Lewis EC, Reznikov L, Ljubanovic D, Hoke TS, Somerset H, et al. Cisplatin-induced acute renal failure is associated with an increase in the cytokines interleukin (IL)-1 $\beta$, IL-18, IL-6, and neutrophil infiltration in the kidney. J Pharmacol Exp Ther. (2007) 322:8-15. doi: 10.1124/jpet.107.119792

72. Okui S, Yamamoto H, Li W, Gamachi N, Fujita Y, Kashiwamura S, et al. Cisplatin-induced acute renal failure in mice is mediated by chymase-activated angiotensin-aldosterone system and interleukin-18. Eur J Pharmacol. (2012) 685:149-55. doi: 10.1016/j.ejphar.2012.04.027

73. Nozaki Y, Kinoshita K, Yano T, Asato K, Shiga T, Hino S, et al. Signaling through the interleukin-18 receptor $\alpha$ attenuates inflammation in cisplatin-induced acute kidney injury. Kidney Int. (2012) 82:892-902. doi: $10.1038 /$ ki.2012.226

74. Liu D, Xu M, Ding LH, Lv LL, Liu H, Ma KL, et al. Activation of the Nlrp3 inflammasome by mitochondrial reactive oxygen species: a novel mechanism of albumin-induced tubulointerstitial inflammation. Int J Biochem Cell Biol. (2014) 57:7-19. doi: 10.1016/j.biocel.2014.09.018

75. Sugiyama M, Kinoshita K, Kishimoto K, Shimazu H, Nozaki Y, Ikoma $\mathrm{S}$, et al. Deletion of IL-18 receptor ameliorates renal injury in bovine serum albumin-induced glomerulonephritis. Clin Immunol. (2008) 128:1038. doi: 10.1016/j.clim.2008.03.501

76. Esfandiari E, McInnes IB, Lindop G, Huang F-P, Field M, KomaiKoma M, et al. A proinflammatory role of IL-18 in the development of spontaneous autoimmune disease. J Immunol. (2001) 167:5338-47. doi: 10.4049/jimmunol.167.9.5338

77. Kinoshita K, Yamagata T, Nozaki Y, Sugiyama M, Ikoma S, Funauchi $\mathrm{M}$, et al. Blockade of IL-18 receptor signaling delays the onset of autoimmune disease in MRL-Fas lpr mice. J Immunol. (2004) 173:5312-8. doi: 10.4049/jimmunol.173.8.5312

78. Schirmer B, Wedekind D, Glage S, Neumann D. Deletion of IL-18 expression ameliorates spontaneous kidney failure in MRLlpr Mice. PLoS ONE. (2015) 10:e0140173. doi: 10.1371/journal.pone.0140173

79. Bossù $\mathrm{P}$, Neumann D, Del Giudice E, Ciaramella A, Gloaguen I, Fantuzzi $\mathrm{G}$, et al. IL-18 cDNA vaccination protects mice from spontaneous lupuslike autoimmune disease. Proc Natl Acad Sci USA. (2003) 100:14181-6. doi: 10.1073/pnas.2336094100

80. Bani-Hani AH, Leslie JA, Asanuma H, Dinarello CA, Campbell MT, Meldrum DR, et al. IL-18 neutralization ameliorates obstruction-induced epithelial-mesenchymal transition and renal fibrosis. Kidney Int. (2009) 76:500-11. doi: 10.1038/ki.2009.216

81. Hirooka Y, Nozaki Y, Niki K, Inoue A, Sugiyama M, Kinoshita K, et al. Foxp3-positive regulatory $\mathrm{T}$ cells contribute to antifibrotic effects in renal fibrosis via an interleukin-18 receptor signaling pathway. Front Med. (2020) 7:604656. doi: 10.3389/fmed.2020.604656

82. Parikh CR, Jani A, Melnikov VY, Faubel S, Edelstein CL. Urinary interleukin18 is a marker of human acute tubular necrosis. Am J Kidney Dis. (2004) 43:405-14. doi: 10.1053/j.ajkd.2003.10.040

83. Parikh CR, Jani A, Mishra J, Ma Q, Kelly C, Barasch J, et al. Urine NGAL and IL-18 are predictive biomarkers for delayed graft function following kidney transplantation. Am J Transplant. (2006) 6:1639-45. doi: 10.1111/j.1600-6143.2006.01352.x

84. Liu Y, Guo W, Zhang J, Xu C, Yu S, Mao Z, et al. Urinary interleukin 18 for detection of acute kidney injury: a meta-analysis. Am J Kidney Dis. (2013) 62:1058-67. doi: 10.1053/j.ajkd.2013.05.014

85. Lin X, Yuan J, Zhao Y, Zha Y. Urine interleukin-18 in prediction of acute kidney injury: a systemic review and meta-analysis. J Nephrol. (2014) 28:716. doi: 10.1007/s40620-014-0113-9

86. Siew ED, Ikizler TA, Gebretsadik T, Shintani A, Wickersham N, Bossert F, et al. Elevated urinary IL-18 levels at the time of ICU admission predict adverse clinical outcomes. Clin J Am Soc Nephrol. (2010) 5:1497-505. doi: 10.2215/CJN.09061209

87. Krawczeski CD, Goldstein SL, Woo JG, Wang Y, Piyaphanee N, Ma Q, et al. Temporal relationship and predictive value of urinary acute kidney injury biomarkers after pediatric cardiopulmonary bypass. J Am Coll Cardiol. (2011) 58:2301-9. doi: 10.1016/j.jacc.2011.08.017
88. Parikh CR, Mishra J, Thiessen-Philbrook H, Dursun B, Ma Q, Kelly C, et al. Urinary IL-18 is an early predictive biomarker of acute kidney injury after cardiac surgery. Kidney Int. (2006) 70:199-203. doi: 10.1038/sj.ki.5001527

89. Washburn KK, Zappitelli M, Arikan AA, Loftis L, Yalavarthy R, Parikh $\mathrm{CR}$, et al. Urinary interleukin-18 is an acute kidney injury biomarker in critically ill children. Nephrol Dial Transplant. (2008) 23:566-72. doi: $10.1093 / \mathrm{ndt} / \mathrm{gfm} 638$

90. Kinsey GR, Li L, Okusa MD. Inflammation in acute kidney injury. Nephron Exp Nephrol. (2008) 109:e102-7. doi: 10.1159/000142934

91. Lieberthal W, Triaca V, Levine J. Mechanisms of death induced by cisplatin in proximal tubular epithelial cells: apoptosis vs. necrosis. Am J Physiol. (1996) 270:700-8. doi: 10.1152/ajprenal.1996.270.4.F700

92. Kinjyo I, Hanada T, Inagaki-Ohara K, Mori H, Aki D, Ohishi M, et al. SOCS1/JAB is a negative regulator of LPS-induced macrophage activation. Immunity. (2002) 17:583-91. doi: 10.1016/S1074-7613(02)00446-6

93. Pressler BM, Falk RJ, Preston CA. Interleukin-18, neutrophils, and ANCA. Kidney Int. (2006) 69:424-5. doi: 10.1038/sj.ki.5000080

94. Hewins P, Morgan MD, Holden N, Neil D, Williams JM, Savage COS, et al. IL-18 is upregulated in the kidney and primes neutrophil responsiveness in ANCA-associated vasculitis. Kidney Int. (2006) 69:605-15. doi: $10.1038 /$ sj.ki.5000167

95. Hultgren O, Andersson B, Hahn-Zoric M, Almroth G. Serum concentration of interleukin-18 is up-regulated in patients with ANCA-associated vasculitis. Autoimmunity. (2007) 40:529-31. doi: 10.1080/08916930701622783

96. Shi B, Ni Z, Cao L, Zhou M, Mou S, Wang Q, et al. Serum IL18 is closely associated with renal tubulointerstitial injury and predicts renal prognosis in IgA nephropathy. Mediat Inflamm. (2012) 2012:728417. doi: $10.1155 / 2012 / 728417$

97. Kitching AR, Turner AL, Wilson GRA, Semple T, Odobasic D, Timoshanko JR, et al. IL-12p40 and IL-18 in crescentic glomerulonephritis: IL-12p40 is the key Th1-defining cytokine chain, whereas IL-18 promotes local inflammation and leukocyte recruitment. J Am Soc Nephrol. (2005) 16:202333. doi: 10.1681/ASN.2004121075

98. Hanly JG, O’Keeffe AG, Su L, Urowitz MB, Romero-Diaz J, Gordon $\mathrm{C}$, et al. The frequency and outcome of lupus nephritis: results from an international inception cohort study. Rheumatology. (2016) 55:252-62. doi: 10.1093/rheumatology/kev311

99. Mende R, Vincent FB, Kandane-Rathnayake R, Koelmeyer R, Lin E, Chang J, et al. Analysis of serum interleukin (IL)-1 $\beta$ and IL18 in systemic lupus erythematosus. Front Immunol. (2018) 9:1250. doi: 10.3389/fimmu.2018.01250

100. Jafari-Nakhjavani MR, Abedi-Azar S, Nejati B. Correlation of plasma interleukin-18 concentration and severity of renal involvement and disease activity in systemic lupus erythematosus. J Nephropathol. (2016) 5:28-33. doi: 10.15171/jnp.2016.05

101. Liang D, Ma W, Yao C, Liu H, Chen X. Imbalance of interleukin 18 and interleukin 18 binding protein in patients with lupus nephritis. Cell $\mathrm{Mol}$ Immunol. (2006) 3:303-6.

102. Park MC, Park YB, Lee SK. Elevated interleukin-18 levels correlated with disease activity in systemic lupus erythematosus. Clin Rheumatol. (2004) 23:225-9. doi: 10.1007/s10067-004-0867-x

103. Calvani N, Richards HB, Tucci M, Pannarale G, Silvestris F. Upregulation of IL-18 and predominance of a Th1 immune response is a hallmark of lupus nephritis. Clin Exp Immunol. (2004) 138:171-8. doi: $10.1111 /$ j.1365-2249.2004.02588.x

104. Wu CY, Yang HY, Yao TC, Liu SH, Huang JL. Serum IL18 as biomarker in predicting long-term renal outcome among pediatric-onset systemic lupus erythematosus patients. Medicine. (2016) 95:e5037. doi: 10.1097/MD.00000000000 05037

105. Navarro-González JF, Mora-Fernández C. The role of inflammatory cytokines in diabetic nephropathy. J Am Soc Nephrol. (2008) 19:433-42. doi: 10.1681/ASN.2007091048

106. Araki S, Haneda M, Koya D, Sugimoto T, Isshiki K, Chin-Kanasaki M, et al. Predictive impact of elevated serum level of IL-18 for early renal dysfunction in type 2 diabetes: An observational follow-up study. Diabetologia. (2007) 50:867-73. doi: 10.1007/s00125-006-0586-8 
107. Nakamura A, Shikata K, Hiramatsu M, Nakatou T, Kitamura T, Wada J, et al. Serum interleukin-18 levels are associated with nephropathy and atherosclerosis in Japanese patients with type 2 diabetes. Diabetes Care. (2005) 28:2890-5. doi: 10.2337/diacare.28.12.2890

108. Moriwaki Y, Yamamoto T, Shibutani Y, Aoki E, Tsutsumi Z, Takahashi S, et al. Elevated levels of interleukin-18 and tumor necrosis factor- $\alpha$ in serum of patients with type 2 diabetes mellitus: relationship with diabetic nephropathy. Metabolism. (2003) 52:605-8. doi: 10.1053/meta.2003.50096

109. Miyauchi K, Takiyama Y, Honjyo J, Tateno M, Haneda M. Upregulated IL-18 expression in type 2 diabetic subjects with nephropathy: TGF- $\beta 1$ enhanced IL-18 expression in human renal proximal tubular epithelial cells. Diabetes Res Clin Pract. (2009) 83:190-9. doi: 10.1016/j.diabres.2008.11.018

110. Klahr S, Morrissey J. Obstructive nephropathy and renal fibrosis. Am J Physiol Ren Physiol. (2002) 283:861-75. doi: 10.1152/ajprenal.00362.2001

111. Boor P, Floege J. Chronic kidney disease growth factors in renal fibrosis. Clin Exp Pharmacol Physiol. (2011) 38:441-450. doi: 10.1111/j.1440-1681.2011.05487.x

112. Zhang H, Hile KL, Asanuma H, Vanderbrink B, Franke EI, Campbell MT, et al. IL-18 mediates proapoptotic signaling in renal tubular cells through a Fas ligand-dependent mechanism. Am J Physiol Ren Physiol. (2011) 301:1718. doi: 10.1152/ajprenal.00339.2010

113. Rhee AC, Cain AL, Hile KL, Zhang H, Matsui F, Meldrum KK. IL-18 activation is dependent on Toll-like receptor 4 during renal obstruction. $J$ Surg Res. (2013) 183:278-84. doi: 10.1016/j.jss.2012.11.038

114. Meldrum KK, Zhang H, Hile KL, Moldower LL, Dong Z, Meldrum DR. Profibrotic effect of interleukin-18 in HK-2 cells is dependent on stimulation of the toll-like receptor 4 (TLR4) promoter and increased TLR4 expression. J Biol Chem. (2012) 287:40391-99. doi: 10.1074/jbc.M112.402420

115. Qin C, Zhou L, Hu Z, Zhang S, Yang S, Tao Y, et al. Dysregulation of immune response in patients with coronavirus 2019 (COVID-19) in Wuhan, China. Clin Infect Dis. (2020) 71:762-8. doi: 10.1093/cid/ciaa248

116. Yang Y, Shen C, Li J, Yuan J, Wei J, Huang F, et al. Plasma IP-10 and MCP-3 levels are highly associated with disease severity and predict the progression of COVID-19. J Allergy Clin Immunol. (2020) 146:119-27.e4. doi: 10.1016/j.jaci.2020.04.027

117. Huang C, Wang Y, Li X, Ren L, Zhao J, Hu Y, et al. Clinical features of patients infected with 2019 novel coronavirus in Wuhan, China. Lancet. (2020) 395:497-506. doi: 10.1016/S0140-6736(20)30183-5
118. Kolhe N V., Fluck RJ, Selby NM, Taal MW. Acute kidney injury associated with COVID-19: a retrospective cohort study. PLoS Med. (2020) 17:e1003406. doi: 10.1371/journal.pmed.1003406

119. Su H, Yang M, Wan C, Yi LX, Tang F, Zhu HY, et al. Renal histopathological analysis of 26 postmortem findings of patients with COVID-19 in China. Kidney Int. (2020) 98:219-27. doi: 10.1016/j.kint.2020.04.003

120. Hamming I, Cooper ME, Haagmans BL, Hooper NM, Korstanje R, Osterhaus A, et al. The emerging role of ACE2 in physiology and disease. J Pathol. (2007) 212:1-11. doi: 10.1002/path.2162

121. Calomeni E, Satoskar A, Ayoub I, Brodsky S, Rovin BH, Nadasdy T. Multivesicular bodies mimicking SARS-CoV-2 in patients without COVID-19. Kidney Int. (2020) 98:233-4. doi: 10.1016/j.kint.2020.05.003

122. Satiş H, Özger HS, Aysert Yildiz P, Hizel K, Gulbahar Ö, Erbaş G, et al. Prognostic value of interleukin-18 and its association with other inflammatory markers and disease severity in COVID-19. Cytokine. (2021) 137:155302. doi: 10.1016/j.cyto.2020.155302

123. Rodrigues TS, de Sá KSG, Ishimoto AY, Becerra A, Oliveira S, Almeida $\mathrm{L}$, et al. Inflammasomes are activated in response to SARS-cov-2 infection and are associated with COVID-19 severity in patients. J Exp Med. (2020) 218:e20201707. doi: 10.1084/jem.20201707

124. Lu L, Zhang $H$, Zhan M, Jiang J, Yin $H$, Dauphars DJ, et al. Preventing mortality in COVID-19 patients: which cytokine to target in a raging storm? Front Cell Dev Biol. (2020) 8:677. doi: 10.3389/fcell.2020. 00677

125. Stone JH, Frigault MJ, Serling-Boyd NJ, Fernandes AD, Harvey L, Foulkes AS, et al. Efficacy of tocilizumab in patients hospitalized with Covid-19. N Engl J Med. (2020) 383:2333-44. doi: 10.1056/NEJMoa2028836

Conflict of Interest: The authors declare that the research was conducted in the absence of any commercial or financial relationships that could be construed as a potential conflict of interest.

Copyright (c) 2021 Hirooka and Nozaki. This is an open-access article distributed under the terms of the Creative Commons Attribution License (CC BY). The use, distribution or reproduction in other forums is permitted, provided the original author(s) and the copyright owner(s) are credited and that the original publication in this journal is cited, in accordance with accepted academic practice. No use, distribution or reproduction is permitted which does not comply with these terms. 